\title{
Evaluation of Histopathologic Results of Testicular Tumors in Antalya: Multi Center Study
}

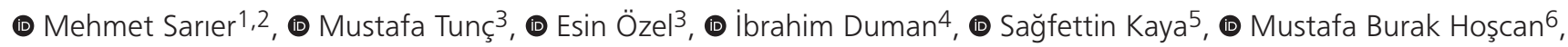

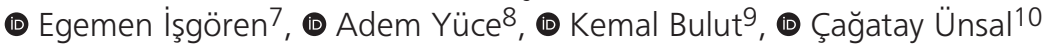 \\ ${ }^{1}$ Medical Park Hospital, Clinic of Urology, Antalya, Turkey \\ 2 Istinye University Faculty of Medicine, Department of Urology, Istanbul, Turkey \\ ${ }^{3}$ Antalya Pathology Laboratories, Division of Pathology, Antalya, Turkey \\ ${ }^{4}$ Medical Park Hospital, Clinic of Urology, Antalya, Turkey \\ ${ }_{5}^{5}$ Medstar Yıldız Hospital, Clinic of Urology, Antalya, Turkey \\ ${ }^{6}$ Anadolu Hospital, Clinic of Urology, Antalya, Turkey \\ ${ }^{7}$ Memorial Hospital, Clinic of Urology, Antalya, Turkey \\ 8 Olimpos Hospital, Clinic of Urology, Antalya, Turkey \\ 9 Likya Hospital, Clinic of Urology, Antalya, Turkey \\ 10 Medical Park Hospital, Clinic of Hematology, Antalya, Turkey
}

\begin{abstract}
Objective: Testicular tumors constitute $1 \%$ of all malignancies in men. Being a relatively uncommon tumor, there are few descriptive studies in the literature. The aim of this study is to retrospectively investigate the histopathological results of testicular tumors in our region.

Materials and Methods: In this descriptive multicenter study, we evaluated the histopathologic results of 124 patients who underwent radical or partial orchiectomy with a diagnosis of testicular tumor between 2011 and 2019 in the region of Antalya, Turkey. All specimens were examined by the pathologists in a single center. Data pertaining to patient age, type of operation, histopathological tumor type, tumor size, and pathological stage of the primary tumor ( $\mathrm{pT}$ ) were analyzed.

Results: The mean age of the 124 patients included in the study was $35.14 \pm 15.3(2-80)$ years. Most $(98.4 \%)$ of the analyzed specimens were radical orchiectomy materials, while only $1.6 \%$ were partial orchiectomy materials. Mean tumor size was $4.01 \pm 2.29(0.5-11) \mathrm{cm}$. Tumor size was $\leq 2 \mathrm{~cm}$ in $29(23.4 \%) \mathrm{specimens}$ and $\geq 2 \mathrm{~cm}$ in $95(76.6 \%)$ specimens. In terms of histopathology, $76.8 \%$ were germ cell tumors, $6.4 \%$ were gender cord-stromal tumors, $4.8 \%$ were ductal canal and rete testis tumors, and $12 \%$ were secondary tumors of the testis. Pathological stage of the pT was pT1 in $46 \%$, pT2 in $39 \%$, and pT3 in $15 \%$ of the patients.

Conclusion: Although patient age and histopathological distribution of testicular tumors were generally consistent with the literature, the average tumor size in the orchiectomy materials was notably large. Initiatives are required to increase public awareness of the importance of early detection. In addition, our findings suggest that urologists feel hesitant to practice testis-sparing surgery despite recommendations in international guidelines.
\end{abstract}

Keywords: Testis, tumor, cancer, seminoma, orchiectomy

\section{Introduction}

Although testicular cancers account for only $1 \%$ of all malignancies in males, they are the most common organ malignancies in men aged 20-40 years (1). Incidence and mortality rates for testicular cancer show significant geographical variation. While the incidence rate is $9.9 / 100,000$ in Scandinavian countries and only $1.3-4 / 100,000$ in the region that includes Turkey, the mortality rates in these areas are $0.27 / 100,000$ and $0.53 / 100,000$, respectively (2). While testicular tumors are still relatively uncommon malignancies, their incidence has increased in the past two decades for unknown reasons (3). Major known risk factors for testicular cancer include undescended testes, a family history of testicular cancer, and the presence of germ cell cancer in the contralateral testis (4). Today, complete cure rates in testicular cancer are close

Cite this article as: Sarıer M, Tunç M, Özel E, Duman I, Kaya S, Hoşcan MB, İşgören E, Yüce A, Bulut K, Ünsal Ç. Evaluation of Histopathologic Results of Testicular Tumors in Antalya: Multi Center Study. Bull Urooncol 2020;19(2):64-67

Address for Correspondence: Mehmet Sarıer, Medical Park Hospital, Clinic of Urology, Antalya; İstinye University Faculty of Medicine, Division of Urology, İstanbul, Turkey Phone: +90 5333324960 E-mail: drsarier@gmail.com ORCID-ID: orcid.org/0000-0002-8656-7416 
to $100 \%$, primarily due to early diagnosis and its highly chemoand radiosensitive nature. The numerous histopathological variations of testicular tumors prompted the World Health Organization (WHO) to update the classification of testicular tumors in 2016 (5). Traditionally, germ cell tumors are the most common histopathological type of testicular cancer. Other tumor types are very rare. In fact, some histopathological types appear in the literature only as case reports. Being relatively uncommon, there are few descriptive studies on testicular cancers in the literature. The aim of this study is to evaluate the histopathologic results of testicular tumors in our region and compare our findings with the literature.

\section{Materials and Methods}

This descriptive multicenter study was approved by the local ethics committee and included six hospitals in the Antalya region. The histopathologic results of 124 patients who underwent radical or partial orchiectomy (PO) due to a diagnosis of testicular tumor between June 2011 and May 2019 were analyzed retrospectively. All specimens were examined by the pathologists in a single center. Data pertaining to patient age, type of operation, pathological tumor type, tumor size, and pathological stage of the primary tumor ( $\mathrm{pT})$ were collected. Tumor size was determined by measuring the maximum diameter of the tumor in centimeters. Pathological staging of PT was done according to the $7^{\text {th }}$ edition of the tumor node metastasis (TNM) staging system for testicular cancer by the American Joint Committee on Cancer (AJCC). This study was designed according to the ethical rules of the 1975 Declaration of Helsinki. Ethics committee approval was received for this study from the ethics committee of Antalya Medical Park Hospital (Complex No: 2019/05 Date: 22.07.2019). Written infromed consent was obtained from patients who participated in this study before surgery.

\section{Statistical Analyses}

All statistical analyses were performed using SPSS statistical software (SPSS for Windows version 16.0 SPSS Inc., Chicago IL, USA). Age and tumor size were expressed as mean \pm standard deviation, while age distribution based on histopathological subgroups was expressed as median (minimum - maximum).

Results

The mean age of the 124 patients included in the study was $35.14 \pm 15.3(2-80)$ years. The distribution of tumors according to age group is shown in Figure 1. Most (98.4\%) of the analyzed specimens were radical orchiectomy materials, while only $1.6 \%$ were PO materials. Mean tumor size was $4.01 \pm 2.29(0.5-11)$ $\mathrm{cm}$. Tumor size was $\leq 2 \mathrm{~cm}$ in 29 patients $(23.4 \%)$ and $\geq 2 \mathrm{~cm}$ in 95 patients (76.6\%). Mean tumor size of the seminomas was $4.85 \pm 2.12(0.6-9) \mathrm{cm}$. Histopathologically, germ cell tumors accounted for $76.8 \%$ of all the testicular neoplasms and $87.2 \%$ of the primary testicular tumors. Gender cord-stromal tumors accounted for $6.4 \%$ and collecting duct and rete testis tumors for $4.8 \%$ of the patients, while $12 \%$ were secondary tumors of the testis (Table 1). Pathological stage of the pT was pT1 in $46 \%$, pT2 in $39 \%$, and pT3 in $15 \%$ of the patients. None of the patients had pTis or pT4.

\section{Discussion}

Tumor size is becoming increasingly important in the clinical course of testicular cancers. Especially for seminoma, which is the most important form of testicular cancer, tumor size is recognized as a risk factor in both staging and occult metastatic disease. One of the important changes in the AJCC $8^{\text {th }}$ edition TNM classification is that in seminomas, pT1 tumors are divided into two subgroups. A tumor size of $3 \mathrm{~cm}$ is determined as the cut-off value. Tumors $<3 \mathrm{~cm}$ are subclassified as pT1a and those $>3 \mathrm{~cm}$ as $\mathrm{T1} \mathrm{b}$ (6). In addition, a tumor size of $>4 \mathrm{~cm}$ and/or the presence of rete testis involvement in stage 1 seminomas was also shown in meta-analyses to be a risk factor for metastatic disease $(7,8)$. The average seminoma size was $4.85 \pm 2.12 \mathrm{~cm}$ in the present study, which was not reassuring. In another study on testicular tumors conducted approximately 2 decades ago in our region, the mean tumor size in seminoma specimens was $4.92 \pm 3.03 \mathrm{~cm}$ (9). This demonstrates that unfortunately, there

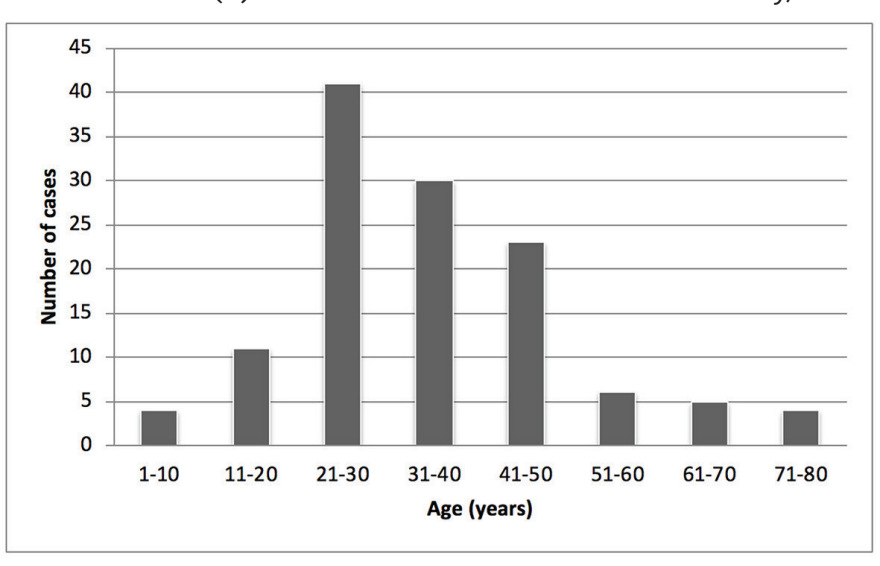

Figure 1. Age distribution of patients with testicular tumors

\begin{tabular}{|l|l|l|}
\hline \multicolumn{3}{|l|}{ Table 1. Histopathological distribution of testicular tumors } \\
\hline Testis Tumors & $\%(\mathrm{n})$ & Age (median) \\
\hline A) Germ Cell Tumors & $76.8 \%$ & \\
\hline Seminoma & $32.3 \%(40)$ & $35(24-62)$ \\
\hline Embryonal Carcinoma & $15.3 \%(19)$ & $28(18-46)$ \\
\hline Mixed Germ Cell Tumors & $22.6 \%(28)$ & $26.5(17-52)$ \\
\hline Yolk Sac Tumors & $4 \%(5)$ & $20(2-28)$ \\
\hline Teratoma & $2.4 \%(3)$ & $27(7-40)$ \\
\hline B) Gender Cord-Stromal Tumors & $6.4 \%$ & \\
\hline Leydig Cell Tumors & $4 \%(5)$ & $40(25-80)$ \\
\hline Sertoli Cell Tumors & $1.6 \%(2)$ & $50.5(31-70)$ \\
\hline Fibroma & $0.9 \%(1)$ & 43 \\
\hline C) Collecting Duct and Rete Testis Tumors & $\mathbf{4 . 8 \%}$ & \\
\hline Adenomatoid Tumors & $4.8 \%(6)$ & $45.5(27-72)$ \\
\hline D) Secondary Tumors & $12 \%$ & \\
\hline Lymphoma & $6.4 \%(8)$ & $54(36-74)$ \\
\hline Leukemia & $4 \%(5)$ & $11(7-45)$ \\
\hline Urothelial Carcinoma Metastases & $1.6 \%(2)$ & $71.5(71-72)$ \\
\hline & $100 \%(124)$ & \\
\hline & & \\
\hline
\end{tabular}


has been no improvement in tumor size at time of diagnosis over the past two decades.

Tumor size is also important in surgical planning. Although radical orchiectomy is currently the gold standard treatment for testicular tumors, PO is a good alternative in selected patients. The preservation of testicular functions with $P O$ is valuable for sustaining testosterone production and spermatogenesis. Mid- and long-term follow-up studies have suggested that PO is not associated with any significant risk of local or distant recurrence that may cause progression (10). Keske et al. (11) reported that of 13 patients who underwent PO due to testicular tumors, only 1 exhibited local recurrence during an average follow-up period of 44 month. The American Urological Association 2019 guidelines state that PO can be considered for tumors $\leq 2 \mathrm{~cm}$ in size in the presence of normal serum tumor markers ( $\beta$ human chorionic gonadotropin and $\alpha$-fetoprotein), a functionally or anatomically solitary testis, or bilateral synchronous testicular tumors (12). The recent European Urology Association guidelines do not specify a size but states that only masses smaller than $30 \%$ of the testis are candidates for PO (4). However, urologists still seem hesitant about this surgical method. It was reported in a large series in the United States that PO was performed in only $2.21 \%$ of 5,365 patients with tumors $2 \mathrm{~cm}$ or smaller (13). In our series, PO was successfully performed in 2 (6.9\%) of the 29 (23.4\%) patients with testicular tumors $\leq 2 \mathrm{~cm}$ in size that were eligible for PO. We believe that urologists have reservations regarding $\mathrm{PO}$, and that rates of testis-sparing surgery will increase as the results of large series with follow-up are published.

The most important point here is the size of the testicular tumors at the time of diagnosis. Testicular tumors are known to be painless masses, which is the main factor responsible for patients' late presentation to a physician. In our study, the mean testicular tumor size was $4.01 \pm 2.29 \mathrm{~cm}$, with $76.4 \%$ being $\geq 2 \mathrm{~cm}$ in size. This suggests that patients seek medical attention quite late and highlights the importance of raising public awareness, especially among men in the at-risk age group. Testicular self-examination is the easiest and cheapest way to scan testicular tumors (14). Especially raising awareness of regular testis self-examination among men aged 15-45 years will facilitate the detection of tumors when much smaller in size.

The prevalence of secondary tumors of the testis varies considerably according to previous publications. In some studies, only testicular metastases of solid organ tumors were considered secondary tumors, while hematologic malignancies were not included (15). When analyzed in that way, secondary tumors of the testis account for less than $2 \%$ of all testicular tumors (16). In earlier studies, it was shown that prostate adenocarcinoma was the most common pT with testicular metastases $(15,16)$. This was because bilateral orchiectomy was performed routinely in the treatment of advanced prostate adenocarcinoma in the past. In our series, $12 \%$ of the tumors were secondary. If we excluded hematological malignancies, the rate of secondary tumors in the form of organ metastasis was compatible with the literature, which was $1.6 \%$ of all testicular tumors. Both of those cases were urothelial carcinoma metastases. Hematological malignancies represent the largest proportion of secondary testicular tumors. In our study, $87 \%$ of secondary tumors were hematological malignancies and $13 \%$ were solid organ metastases.

As mentioned above, testicular invasion by hematological malignancies constitutes a significant proportion of secondary tumors. There seems to be confusion regarding the definition here. Oncologists avoid defining testicular involvement of hematological malignancies as metastasis, instead describing it as involvement. In our study, about $10.4 \%$ of all patients were hematological malignancies. The relatively high rate of hematologic malignancies in this series might be due to the fact that two of the participating hospitals were regional referral centers for hematological malignancies.

Testicular lymphoma is caused by either primary or secondary infiltration of the testis by malignant/clonal lymphocytes. It accounts for $5 \%$ of all testicular tumors and is the most important cause of testicular masses after the age of 60 . Primary testicular lymphoma is very rare and usually reported in the literature in case reports (17). In our series, patients with lymphoma were slightly younger compared to the literature, with a mean age of 54. One of the patients with lymphoma had primary testicular lymphoma and the others had relapses. Twenty percent of extramedullary lymphomas are located in the testes, which is an indicator of poor prognosis. Bilateral involvement is seen in up to $35 \%$ of patients (18). About $80-90 \%$ of testicular lymphomas are diffuse large B-cell lymphomas. All of the lymphomas in our study except in one patient were diffuse large B-cell lymphomas.

Leukemic infiltration is another hematological malignancy that involves the testes and is among the secondary testicular tumors. It represents an important place among testicular tumors, especially in the pediatric age group. As with lymphoma, the testes are also the most common site of extramedullary recurrence of leukemia after the central nervous system. In the pediatric patients with acute lymphoid leukemia, up to $5-8 \%$ of patients can have primary involvement or relapse in testis (19). Lymphoblastic cells that pass through the blood-testis barrier are protected from chemotherapeutic agents and involvement occurs as a result of their proliferation (20). In our study, patients with testicular leukemic infiltration had a mean age of 11 years and represented a remarkable $4 \%$ of all testicular tumors. In addition, all of the patients were diagnosed as having acute lymphoblastic leukemia. Orchiectomy or radiotherapy (RT) may be considered in the treatment of the leukemic involvement of the testes $(19,21)$. Neither approach provides superior outcomes in patients with unilateral involvement. In principle, however, orchiectomy is advantageous because it definitively eliminates leukemic infiltration of the testes (22). Patients in whom RT is planned should be informed of the possibility of permanent deterioration of gonadal functions after RT (23).

Adenomatoid tumors are benign and they are the most common form of paratesticular tumors (24). Adenomatoid tumors are indistinguishable from malignant testicular tumors both in terms of clinical findings and imaging; therefore, radical orchiectomy is often performed in these tumors (25). Notably, adenomatoid tumors were seen in 6 patients and accounted for $4.8 \%$ of all testicular tumors in our study. In addition, only one of these patients underwent PO. Testis-sparing surgery should definitely be considered in these patients. 
Testicular fibroma was observed in one patient in our study. Testicular fibroma is a benign tumor in the thecoma-fibroma group of gender cord-stromal tumors according to the 2016 WHO classification. Testicular fibroma is a very rare tumor, with fewer than 30 patients reported in the literature (26).

\section{Study Limitations}

This study had certain limitations. Only pathological tumor staging was done in patients with primary testicular tumor. The lack of clinical staging of the pT might be considered a limitation.

\section{Conclusion}

Although age and histopathological distribution of testicular tumors in our region were generally consistent with the literature, tumor size in the orchiectomy materials was remarkably large. Initiatives are required to increase public awareness of the importance of early diagnosis in testicular cancer, especially men between the ages of 15 and 45 years. In addition, despite recommendations in international guidelines, our findings show that urologists are hesitant to practice testis-sparing surgery.

\section{Acknowledgements}

Publication: The results of the study were not published in full or in part in form of abstracts.

Contribution: There is not any contributors who may not be listed as authors.

Conflict of Interest: No conflict of interest was declared by the authors.

Financial Disclosure: The authors declared that this study received no financial support.

\section{Ethics}

Ethics Committee Approval: Ethics committee approval was received for this study from the ethics committee of Antalya Medical Park Hospital (Complex No: 2019/05 Date: 22.07.2019).

Informed Consent: Written infromed consent was obtained from patients who participated in this study before surgery.

Peer-review: Externally peer-reviewed.

\section{Authorship Contributions}

Concept: M.S., Design: I.D., Data Collection or Processing: M.T., E.Ö., Analysis or Interpretation: S.K., M.B.H., Literature Search: E.I., A.Y., Writing: M.S.

\section{References}

1. Ferlay J, Soerjomataram I, Dikshit R, et al. Cancer incidence and mortality worldwide: Sources, methods and major patterns in GLOBOCAN 2012. Int J Cancer 2015;136:359-386.

2. Cheng L, Albers P, Berney DM, et al. Testicular cancer. Nat Rev Dis Prim 2018;4:29.

3. Ghazarian AA, Kelly SP, Altekruse SF, Rosenberg PS, McGlynn KA. Future of testicular germ cell tumor incidence in the United States: Forecast through 2026. Cancer 2017;123:2320-2328.

4. Albers P, Albrecht W, Algaba F, Al E. European Association of Urology, Guidelines on Testicular Cancer 2018.
5. Moch $\mathrm{H}$, Cubilla AL, Humphrey PA, Reuter VE, Ulbright TM. The 2016 WHO Classification of Tumours of the Urinary System and Male Genital Organs-Part A: Renal, Penile, and Testicular Tumours. Eur Urol 2016;70:93-105.

6. Magers MJ, Idrees MT. Updates in Staging and Reporting of Testicular Cancer. Surg Pathol Clin 2018;11:813-824.

7. Aparicio J. Prognostic factors for relapse in stage I testicular seminoma: tumor size and rete testis invasion revisited. Clin Transl Oncol. 2018;20:1358-1359.

8. Boormans JL, Mayor de Castro J, Marconi L, et al. Testicular Tumour Size and Rete Testis Invasion as Prognostic Factors for the Risk of Relapse of Clinical Stage I Seminoma Testis Patients Under Surveillance: a Systematic Review by the Testicular Cancer Guidelines Panel. Eur Urol 2018;73:394-405.

9. Oztekin S. Testisin Germ Hücreli Tümörlerinde Fas, FasL, ve p27 ekspresyonu: Histopatolojik alt tiplerine göre ve erişkinde normal testis dokusu ile karşılaştııılması. Akdeniz Univ. 2001.

10. Djaladat H. Organ-sparing surgery for testicular tumours. Curr Opin Urol 2015;25:116-120.

11. Keske $M$, Canda $A E$, Atmaca $A F$, et al. Testis-sparing surgery: Experience in 13 patients with oncologic and functional outcomes. Can Urol Assoc J 2018;13:83-88.

12. Stephenson A, Eggener SE, Bass EB, et al. Diagnosis and Treatment of Early Stage Testicular Cancer: AUA Guideline. J Urol 2019;202:272-281.

13. Alanee S, Clemons J, Holland B, Nutt M, Dynda D. The Utilization of Partial Orchiectomy in Treating Small Testicular Tumors in the United States. Int J Cancer Clin Res 2017;4:1-7.

14. Kuzgunbay B, Yaycioglu O, Soyupak B, et al. Public awareness of testicular cancer and self-examination in Turkey: A multicenter study of Turkish Urooncology Society. Urol Oncol Semin Orig Investig 2013;31:386-391.

15. Ulbright TM, Young RH. Metastatic Carcinoma to the Testis. Am J Surg Pathol 2008;32:1683-1693.

16. Dutt N, Bates AW, Baithun SI. Secondary neoplasms of the male genital tract with different patterns of involvement in adults and children. Histopathology 2000;37:323-331.

17. Tombolini F, Lacetera V, Gini G, et al. Primary B-cell lymphoblastic lymphoma of the testis. Arch Ital di Urol e Androl 2014;86:400.

18. Sarici H, Telli O, Eroglu M. Bilateral testicular germ cell tumors Bilateral testiküler germ hücreli tümörler. Turkish J Urol 2013;39:249-252.

19. Santos Patto de Góes L, Iglesias Lopes R, Henrique Arcos Campos $\mathrm{O}$, et al. Recurrence of acute myeloid leukemia in cryptorchid testis: case report Recidiva de leucemia mieloide aguda em testículo criptorquídico: relato de caso 2014;12:109-120.

20. Eren MŞ, Koç M, Ören H, Özkal Ş, Durak H. Testis Scintigraphy in a Patient with Acute Lymphoblastic Leukemia. Malecular Imaging Radionucl Ther 2015;23:35-38.

21. Gutjahr P, Humpl T. Testicular lymphoblastic leukemia/lymphoma. World J Urol 1995;13:230-232.

22. Locatelli F, Schrappe M, Bernardo ME, Rutella S. How i treat relapsed childhood acute lymphoblastic leukemia. Blood 2012;120:2807-2816

23. Locatelli F, Gambarana D, Zecca M, et al. Prophylactic orchiectomy after bone marrow transplantation for boys with acute lymphoblastic leukaemia and previous testicular relapse. Bone Marrow Transplant. 1991;8(Suppl 1):57-59.

24. Liu W, Wu R, Yu Q. Adenomatoid tumor of the testis in a child. I Pediatr Surg 2011;46:15-17.

25. Urkmez A, Akan S, Ozsoy E, Sahin A, Koca O, Ishak Ozturk M. Diagnosis and Treatment Of Paratesticular Adenomatoid Tumors. I Coll Physicians Surg Pakistan 2018;28:S217-S219.

26. Tegeltija D, Lovrenski A, Panjkovic M, Eri Z, Klem I. Testicular (gonadal stromal) fibroma: Case report. Arch Oncol 2012;20:26-27. 